\title{
Towards a Modern Design of Undeveloped City Using a Spatial Modelling Analysis; a Case Study of Irbid City in Jordan
}

\author{
Zaid A.O. Aldeek ${ }^{1 *}$, Mahmoud Z. Mistarihi ${ }^{2}$ \\ ${ }^{1}$ Department of Architecture, Hijjawi Faculty of Engineering Technology, Yarmouk University, Irbid 21163, Jordan \\ ${ }^{2}$ Department of Industrial Engineering, Hijjawi Faculty of Engineering Technology, Yarmouk University, Irbid 21163, Jordan
}

Corresponding Author Email: zaid.d@yu.edu.jo

https://doi.org/10.18280/ijsdp.150415

Received: 10 May 2019

Accepted: 13 March 2020

\section{Keywords:}

urban regeneration, Irbid city future, urban and architectural planning, spectrum model, spatial model, parametric matrix processing, integral planning model

\begin{abstract}
In the past, Jordanian cities were just small centers, with no planning systems. Today, many of these cities have expanded in response to emergency urbanization and ongoing political crises. The resulting development has irreversibly modified the urban landscape. Studies of urban conditions in Jordanian cities, particularly, Irbid, are key to understanding how rapid growth has altered its architectural and urban landscape. This paper focuses on the problem of urban regeneration and requalification to identify the variables driving informal development in Irbid. Understanding the real factors, as illegal and abusive land use, at play versus unnatural development where classical approaches are not suitable for understanding the problem. Highlighting policies, strategies, and tools needed to identify transformation trends of cities like Irbid, to produce hypothesis of sustainable and suitable development. Results show that to propose innovative hypothesis we must first research evolution mechanisms and their transformation effects. Using tools that define conditions of under developing that govern transformations in our case study. A spatial modelling would be an interpretation model that combines effects and causes, of the cited under developing situation in future projection of sustainable development. The proposed spatial modelling, "Integral Planning Model" (IPM), throw investigations and interviews and simulations try to build a parametric matrix processing able to help the planners and policy makers to put up suitable strategies.
\end{abstract}

\section{INTRODUCTION}

\subsection{Irbid evolution and history}

Irbid or (Arabella) locates in the northern Jordan and consider as the second major city in the country with more than 1.2 million inhabitants. Irbid city dates to the Bronze Age where the discovered graves and artefacts showed that Irbid has been inhabited since the Bronze Age. Moreover, the pieces of wall stones and pottery that were found at Irbid hill were estimated to the year 3200 B.C. This city was one of the major trade's centers during the Greek age. In the Romanian age, Arabella was known for its agricultural wealth due to its soil fertility and moderate climate. Historically, Irbid played a significant role in the Romanian Empire, as it was one of ten most important cities of the Middle East (Decapolis). The main historical remains of the ancient city are now located under Irbid hill (Tal Irbid), which is an artificial hill that was built during the Greek age.

Irbid became under the Muslim domain in 636 A.C during the first Islamic expansions, it did not acquire importance as a military center due to its flat plan morphology. In the Ayyubid period acquire more important for its strategic position as support in the against the holy crusade. In Mameluke, the city became an important center of communications and connection between the north and south parts (Syria and Egypt) of Mameluke state. During the Ottoman era, the city continued to have the same functions as in the Ayyubid period. We note that Irbid during the overall Islamic period did not acquire an important role due to the flat morphology. Important centers were in mountain zones for military reasons [1].

\subsection{Irbid modern transformation}

Briefly, the most important transformations in the modern era were in 1948 and 1967, as consequence of geopolitical changes, represented by the occupation of Israel of many parts of Palestine, hundreds of thousands of Palestinians left their country, and start making their way to Irbid, which was the nearest city to Palestine's borders. Irbid, before this transformation, was a little town with some thousands of habitats. The city from 1948 to 2016 is increased 230 times in meanings of population and dimensions. As exposed later this demographic boom caused a multiple of unresolved issues, rapid urbanization, emergency planning, informal economy and informal use of the territory.

The paradox, that Irbid nowadays has extended infrastructures, high population density, intensive activities, and commercial exchanges but it is characterized by plans of development that consider Irbid as a small center [2]. Noted, studying this city that there are insufficient resources and studies to support research with statistics and numbers. Comprehensive and comparative studies of urban and architectural development scenarios are absent, with just some fragmented studies conducted by local administrations and academic researchers [3]. 
Nowadays, in Irbid, conventional land use and urbanization processes are at odds. Development planning strategies are struggling to deal with market demands and requests, which have ignited debates on the problem of reuse and rehabilitation of the existing built environment in total confusion [4].

The most important transformation in the modern era was in 1948, as seen before, when hundreds of thousands of Palestinians left their country, with many making their way to Irbid. This wave of refugees had major implications for planning. First, to accommodate the refugees, the Jordanian government established a greeting areas and constructed a refugee camp within the inner city, the dimensions of this refugee camp was major of the dimensions of the city itself, this camp constructed in response to an emergency and without any foresight as to their possible consequences in the future. Second, to integrate these camps as modern and functional parts of the city, which does not avenue; producing an unnatural conclusion that effects of temporary transformations became mechanisms of evolution (the extraordinary solutions placed the ordinary planning process).

Later, we will see the rapid growth of the city related to dynamic mechanisms of evolution produced dramatic results and effects on the process of urban and architectural transformation, giving motivations of this study, which can be summarized:

1. The diffused spectral planning models and the absence of prediction models, which play important role in the city transformation.

2. Random constructions and informal trading, and the inappropriate distribution of residential, commercial, and public buildings.

3. Lack of street furniture, absence of enough parking areas and the low level of important public services.

4. Visual pollution caused by shop banners and random displays of goods and clothes on façades.

5. Improper utilization of the built heritage and old buildings.

6. Health problems caused by a lack of infrastructure.

7. Traffic congestion, and the high level of traffic difficulties.

The research study aims at overcoming some of the mentioned above problems by providing a basic background on which further studies can draw. Thus, we conducted various investigations, including site visits and interviews, to understand the situation in Irbid and to formulate hypotheses. We drew on both local and international experiences, which deal with the general theme, focusing, particularly, on recent studies of urban regeneration that employed innovative philosophical and scientific approaches.

\section{REVIEW OF RELATED RESEARCH}

By their nature, the urban evolution of cities is both passive and active factors. In a passive sense, they are sites where events take place. In an active sense, they play a major role not only in the evolution of urban systems but also in that of social and economic systems. Essentially, cities attract economic activities and social groups [5]. This study highlights the need of a delicate balance between preservation and transformation. The latter refers to the inappropriate use of buildings, poor quality of some sections of the city, functional inadequacy of the city, and it is very evident state of degradation, (see attached 1: photographic documentation).
The lack of proper environmental planning rules has contributed on creating social problems in Irbid. Furthermore, economic concerns and political crises have contributed to poor urban and building sectors, characterized by the absence of innovative and creative solutions. To address the fragmentation and heterogeneous environment of Irbid today, both conservative and transformative strategies are needed, at various levels [6].

Resources, including adequate planning tools, are required to redesign the city to address complex needs. Furthermore, a high technical level of skills is necessary to propose valid solutions. Both academic studies and practices reflections are required to form an understanding of the interaction between historical and contemporary cities and societies and to develop a clear identity, which can then be shared. Such studies are also needed to focus debates on innovative functions, processes, styles, and technologies of a developed city [7]. In discussing the relationship between innovation and tradition, Fathy [8] described the relationship between human development and historical memory, where both result in the production of information and knowledge about place over generations, forming a collective consciousness.

The continuity with the past results in the maintenance of traditional knowledge and values and elevates human society to another level with regards to architectural and urban transformation, all research models must respect the need for continuity between architectural and urban design [9]. This continuity determines the success of a project or a plan because it determines the future model of the city.

\section{DISCUSSION CONSIDERATIONS \\ AND \\ BACKGROUND}

This research paper presents the results related to Irbid, particularly, the inner city, analyze effects of current urbanization processes and related disastrous effects on the city's development. The study grew out from the need for real transformation of the city, which faces many serious planning problems, in addition to traffic congestion, an absence of adequate and vital infrastructures, and a high level of different types of pollution. Confronting approaches used and being problems, which are in direct contact with each other, sustainable development planning must consider the local culture, the poor state of current buildings, and evolution modality of urban areas. It should also address the causes of the loss of connectivity between historic areas and the center of the city. In addition to secondary factors effects, such as the impacts of visual pollution on urban areas and infrastructures.

The first major issue in Irbid is how to resolve circulation problems and reduce traffic jams. These problems can be addressed using various interventions, such as smart solutions, which should begin with administrative decentralization, feedback on traffic systems, which would reduce the number employees of urban areas who must reach destination passing the city center. Identifying which activities could be transferred to other zones would also reduce the movement of trucks and other large vehicles through the city. Establishing specific pedestrian zones would also be helpful [10].

Resolving traffic congestion requires an understanding of the typologies of users. As shown by the results of interviews majority of users are forced to cross the center of the city due to an absence of other ways to reach their destinations, (see Table 1, 2). 
Table 1. Motivation of user presence in Irbid city centre (Resource: Authors 2019)

\begin{tabular}{cccc}
\hline Interviews number & Shopping, legal matters and affairs & Crossing for other & Interviews number \\
\hline 100 & 30 & 60 & 10 \\
\hline
\end{tabular}

Table 2. User prefers possibility of use alternative roads as results of interviews (Resource: Authors 2019)

\begin{tabular}{cccc}
\hline Interviews number & If gives major Possibility to save time & If gives possibility to access to the center also & Do not know \\
\hline 100 & 40 & 50 & 10
\end{tabular}

A second important issue is how to define the actual limits of the city, the industrial zones defined in previous master plans are now within urban zones. To better define the limits of the city, traditional buildings and historical identity need to be re-evaluated and included as strategic and vital infrastructures.

A third and crucial issue is how to encourage investment in central areas to boost the fragile and informal economy. The aim of such investments is to encourage users to abandon informal commerce and introduce official and formal sectors of activities, which could be helped and controlled by local and national governments. Encouraging social equity is one of elements that must be debated, particularly, in developing countries [11].

Fourth, the central areas can also be evaluated by restudying the destination of use of buildings and zones. Downtown Irbid is characterized by a lack of balance in destination-use zones, with just day activity zones, offices, commercial activities, and public offices, with exception of some poor-quality housing, residential activity is absent.

Finally, future must reintegrate and incentivize the construction of medium and high-quality residential housing, within center limits, to keep the city alive. In addition, visual pollution caused by publicity panels should be reduced. Moreover, sidewalks should be rehabilitated to improve accessibility and control encroachment by informal commercial traders, who use large parts of sidewalks to display their products.

The present analysis focused on issues that the planners have not previously considered dealing with the city of Irbid. This study contributes to the understanding of the factors that don not permit a normal development and can ignite a new debate about elements necessary for a sustainable development of Irbid. The core concern of this paper was the regeneration of the center of Irbid city. Thus, the status of the city was first studied, followed by consideration of potential regeneration strategies. This study employed a combined approach in its analysis by multiple factors; social, economic, and the current style of urbanization in the region and the city.

\section{DISRUPTION TO FORMAL AND LEGAL PLANNING IN IRBID}

The rapidly increasing of the city of Irbid and the multiple problems related to the flow of immigrates, as seen in paragraph 1.2, produced a multiple planning issues; temporary actions and plans to affront the emergency, political issues as the integration of these refugees or maintaining them in separate zones, speculation, abusive buildings and activities and the absence of strong and competent authority of planning. Multiple planning issues were managed by different parts producing overlapping of different masterplans. As a result of the actuation inability of the basic elements of development.
In this sense, this paper highlights the necessity of innovative methods to assist policymakers towards sustainable development among new prediction and interpretation models.

The on-site analyses pointed to study multiple problems: land use, building forms, traffic circulation and parking, public spaces, pedestrian circulation, public transportation, a proliferation of advertising signs and boards. The interactions between these areas identified the main problems in Irbid city. As a result of these analyses, we identified the following existing problems:

\subsection{The diffused use of spectral planning and absence of prediction models}

Based on interviews and site visits, we amassed enough documentation and data necessary to formulate affirmations that describes problems facing Irbid city. Of note, Irbid lacks an efficient public transportation system, thus, most users travel by private car. Some users in rural areas travel into the city by taxis or minibuses, producing a high vehicle-user ratio in the city. From analysis of GIS maps of the city center of Irbid, (See Figure 1), which, crossed by intercity roads from the north verso south and from east verso west. Prior to the unprecedented growth of the city, this was acceptable.

However, the increase in the size of the urban areas surrounding the city grown has led to traffic-related problems, with users having to cross the center to reach their destinations, adding heavy traffic in the city.

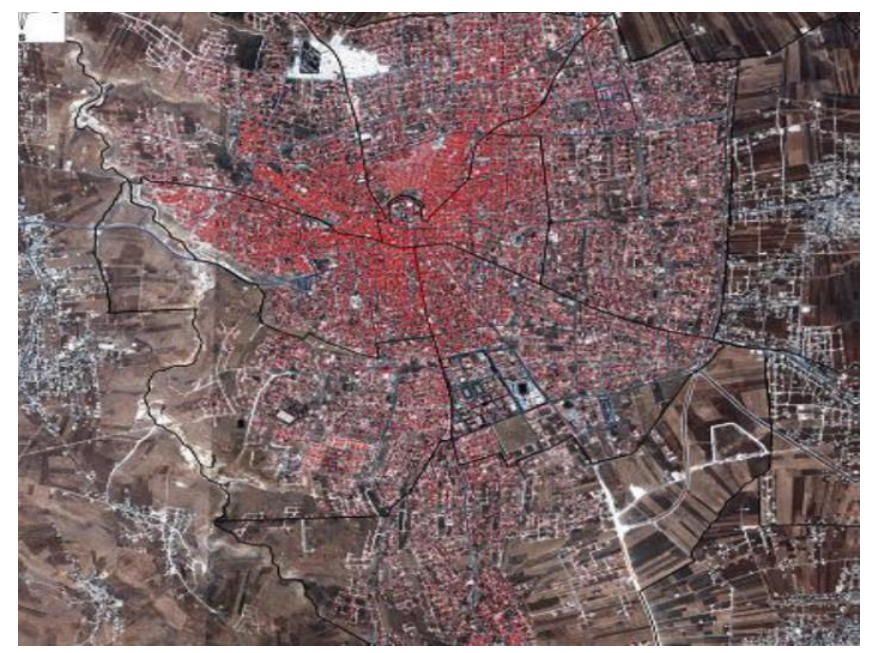

Figure 1. Principal roads connection that cross the city, (Source: Irbid Municipality office of G.I.S. 2016)

In Irbid city, all traffic travels directly through the city center, based on our analyses and the interviews, many users would prefer alternative routes to reach their destinations. The present situation can be attributed to incorrect planning decisions by local administration and planners because they 
did not believe that the city can be transformed from temporary development into an organized and smart city, thus, their strategies have remained focused on day-to-day solutions.

Proposals are needed to address this mindset and the resulting problems. Examples include constructing tunnels to allow users to cross critical zones, creating urban ring roads to different destinations, and limiting traffic access to the city center.

The suggestions could reduce the traffic intensity in the town center. This would produce multiple benefits, such as decreasing traffic flows, increasing pedestrianized areas, increasing available parking areas, reducing emissions, and improving the inhabitants' quality of life.

The absence of pedestrianized areas, the mixed use of streets as sidewalks, and their bad state, in addition to visual pollution and the absence of adequate parking areas, suggest that future urban-design interventions must use innovative strategies and vision.

We highlighted that the problem of traffic congestion in Irbid is not due to the dimensions of the streets or the need to build others but due to their organization and to the rigidity of design and planning processes that have been adopted. Various factors account for traffic congestion in Irbid, including poor street management and incorrect practices, as using sidewalks for trading, by employers. A major cause of traffic congestion is not the dimensions of the streets or the quantity of cars but rather informal trading and outside commerce.

\subsection{Absence of important vital services}

The lack of transportation system, enough parking areas, and circulation norms are evident in Irbid, a city with high population density (one and past million population) requires appropriate planning strategies. In the absence of such design strategies, it will become a marginal, dead city. At present, transportation in Irbid is managed by single small companies or just drivers with a transportation license. This situation has resulted in a marginal and informal transportation sector. Overcoming this difficult situation will require innovative methods as the proposed integral model of transportation planning. Parking and green areas also need to be established in a manner that permits the city to overcome its past planning difficulties.

\subsection{Random constructions and informal trading}

In developed cities, such as Amman, interventions by the Municipal administration and economic investments have led to a rise in land values. In addition, the organized development of projects in Amman gave users a shared value and encouraged them to transform their city [12]. This did not happen in Irbid. because the Municipality of Irbid did not put forward valid development strategies that incentivized activities to challenge the current situation.

These strategies produced new informal trading activities in some zones, an example is the area around Yarmouk University, where commercial activities and residential buildings were considered prestigious a few years ago but are now viewed as low-value, insecure investments.

Other problem is the informal trading, that use public areas, such as sidewalks, to display or store their products. Informal trading cannot contribute to the development of a city, and it constitutes a real handicap to future planning strategies.
4.4 The inappropriate distribution of residential, commercial, and public buildings

Unpredicted events led to the inappropriate distribution of residential, commercial, and public buildings. First, in 1948, Irbid city was the focus of massive immigration because of the Arab-Israeli war. This was followed in 1967 by additional immigration due to the occupation by Israel of Palestinian territory. Subsequent immigration occurred because of the Syrian crisis. The local administration adopted an emergencytype approach to affront the crisis, In the past, the challenge was to deal with a difficult human situation, and this rightly took precedent over urban and architectural realities. We do not seek to deny our recent past but wish to contribute to the discussion of how to change this difficult situation, using tools that can be applied in the prediction of future development.

\subsection{Lack of street furniture, pedestrian zones and public parking}

Overuse and not appropriate adequacy of the infrastructures because of the high use, and the absence of regular maintenance by local administrations have led to decay street furniture's and a lack of public of urban elements. We can speak about "legal abusive" caused of non-application of municipal norms, analyzing the urban situation in Irbid. The local administration is not able to produce and apply suitable norms, this is referred to the spectral planning model, largely discussed in this paper. Urban-management policies in Irbid have been characterized by two approaches: macro interventions that do not focus on real solutions but rather on how to increase the urbanized territory and micro interventions unconnected to an urban vision, highlighting the lack of interpretation model that, define the concept of city unity with connected plans.

\subsection{Visual pollution caused by informal trading and health problems caused by a lack of infrastructures}

Visual pollution influences the development of an emergent city because it contributes to and encourages random and informal commerce. From our research, we note that visual pollution in Irbid city is not just a visual problem it, also, denies accessibility to public spaces. At the time of the emergency situations and subsequent building construction accelerated by market speculation, no attention was paid to the water drainage system or network of health services. Interventions are needed to address these issues. The system and services must be redesigned, considering the increased dimensions of the city and its population density.

\section{RESEARCH FINDINGS}

Based on the analysis carried out in this research paper, the first important finding is as follows: As stated in masterplans, neither the dimensions of the streets nor existing traffic congestion are the main causes of the problems in Irbid city. Instead, the principal causes include the inhabitants of the city behaviors as non-respecting of norms, informal trading sectors, visual pollution, poor-quality infrastructure, and illegal and abusive use of landscapes and sidewalks.

In this paper, we emphasize the urgent need to solve the current problems related to urban planning in Irbid to achieve 
a vision of sustainability and avert "crisis of strategies." The vision includes solving traffic problems and improving accessibility in the city, with policies and regulations that influence and correct the current situation.

The second major finding of the present study is that at present, Irbid suffers from an absence of a shared image of the city, which is a fundamental principle of urban planning. The masterplans presented for Irbid have not taken this shared vision into consideration. Instead, they have focused on fragmented interventions, with the emphasis on resolving single problems, paying no attention to the city as an entire entity (unit). As noted by Mario Botta, (famous architect and urban planner), the city must be a space that values a range of human activities: social, economic, and cultural in appropriate vision of the city and its architecture [13]. The evolution of Irbid is a clear example of the fragmentation of strategies that govern the city. Over the years, it has grown in different directions, with no connections between emergency planning, transportation planes, the historical center conservation and no coordination between major projects and policies. In Jordan, generally, there is a marked separation between architecture and urban planning and policies. It is evident that the relationship between architecture and the city is a major determinant of future development scenarios, previously described the relationship between collective urban artefacts and individuals as unique, with each respecting the other. Rossi and Eisenman [9] referred to architecture as a cultural movement, opening a critical debate about architecture as part of the city. Also noted that there is a direct relationship between urban and the buildings construction development.

The third determinant finding is the necessity of a social compatible model (Eco-solidarity model). Dealing with the diffused informal activities in the discussion related to development transformation's debate. A social compatible model (Eco-solidarity) is seen in two different modes; the first as a system of aims finalized as outcomes, while the second sees it as a process and strategy that enhance conditions to resolve collective goals. The social solidarity model combines individual and community targets aiming to get an acceptable position on the quality of life and on the use of public spaces [14]. This model is based on policies of micro credit organized by local communities, enabling marginal and informal sectors to take part of the process. Social compatible model is vital to see the informal development of the city which produced many informal activities.

Thousands of people work informally using public spaces in the city. Informal trading is one of the major issues that impede the local administration to but in actuation its plan. Thus, informal trading and manufacturing have strong distribution in all parts of the city with relative social and political impacts. Future strategies must take into consideration the informal sector offering a spatial project that predicts their introduction in new projects. These strategies firstly can introduce some areas in future masterplans to be adopted legally from informal traders and manufacturers. Secondly, future development plans must consider the possibility of introducing micro-credit accessibility in this sector with the finality to carry out informal activities into formal ones.

The fourth finding of this study is the importance of employing advanced technologies and advanced interpretation models in underdeveloped cities, as Irbid, when aiming to address urban and architectural problems.

\section{LACK OF MODELS OF INTERPRETATION AND THE NECESSITY OF INTRODUCING PARAMETRIC PLANNING}

Drawing on elements discussed, efforts in this paper are to introduce parametric planning concept as tool able to understand urban and architectural issues in Irbid and to reduce fragmentations produced from current planning strategies in the evolution of the city [15].

As introduced the city suffers from many problems, (traffic, connections, and spatial distribution), caused from the rapid growth influencing, negatively, the mentality of planners and policy makers. All plans presented in the last years from local authorities are characterized dispersion and fragmentation caused from the absence of tools that connect different issues plans for urban development that overlap different issues without understanding their intersections and nature.

Dispersed and fragmented interventions produced in the years, planning Irbid, highlights the necessity to introduce new tools to understand and combine better urban and architectural development of the city [16]. Seen the complexity of issues that Irbid planning presents we hypnotize the need of a model of interpretation based on the use of parametric planning to simplify the decision process.

Thus, it is possible to make decisions without being influenced from the spectral and current method of planning diffused in Irbid city.

\section{PROPOSED INTEGRAL PLANNING MODEL (IPM)}

Among literature review of urban spatial change modelling and simulation from an international perspective, interviews and site visits of our case study (Irbid), the concept of the model is structured as follows: Firstly, modelling definition, secondly, integrated planning parameters definition (model matrix) which compile effects of policies and strategies giving "acceleration/relay weight for each factor playing role [17]. The use "Matrix of Parameters" introduce social and economic parameters where, other models are lacking. For example, UGM, (Urban growth models), use GIS to model urban growth by mapping where the growth is likely to occur and in addition estimates residential dwelling units and future industrial and mixed-use land use [18].

The outputs from the UGM, (Urban growth models), assist in planning for what investment in municipal services is required. This estimation process is a culmination of bottomup spatial planning and proposals that emanate from the city districts. It considers how vacant land can be used, what percentage of the site can be developed, the residential densities and the likely timeframe for its development, but do not consider social and economic parameters, (See Table 3, 4).

Besides incorporating the desires of spatial planners, the UGM does not recognize that ultimately private investment decisions and other practicalities (especially in the development of state housing by public institutions) influence the prevailing urban development. 
Table 3. Conceptual definition of the proposed integral model of planning: model's framework

\begin{tabular}{cccccc}
\hline Phase 1 & Phase 2 & Phase 3 & Phase 4 & Phase 5 & Phase 6 \\
\hline $\begin{array}{c}\text { Mental abstracting } \\
\text { Mapping Model } \\
\text { (lynch) }\end{array}$ & $\begin{array}{c}\text { Mix } \\
\text { Approach } \\
\text { Model }\end{array}$ & $\begin{array}{c}\text { Environmental } \\
\text { and Spatial } \\
\text { analysis models }\end{array}$ & $\begin{array}{c}\text { Defining parametric design } \\
\text { of architectural and urban } \\
\text { design processes. }\end{array}$ & $\begin{array}{c}\text { Parametric } \\
\text { Matrix of spatial } \\
\text { elements. }\end{array}$ & $\begin{array}{c}\text { Proposed } \\
\text { "Integral Planning } \\
\text { Model” (IPM). }\end{array}$ \\
\hline
\end{tabular}

Table 4. Development of matrix parameters

\begin{tabular}{cccc}
\hline $\begin{array}{c}\text { Defining Urban } \\
\text { Parameters }\end{array}$ & $\begin{array}{c}\text { Analysis of Design } \\
\text { Parameters }\end{array}$ & $\begin{array}{c}\text { Parameters Design } \\
\text { Elements }\end{array}$ & $\begin{array}{c}\text { Inputs for the "Integral } \\
\text { Planning Model” (IPM) }\end{array}$ \\
\hline $\begin{array}{c}\text { Environmental and } \\
\text { Spatial analysis models }\end{array}$ & $\begin{array}{c}\text { Defining architectural } \\
\text { urban parametric design }\end{array}$ & $\begin{array}{c}\text { Parametric Matrix } \\
\text { of spatial elements }\end{array}$ & $\begin{array}{c}\text { Proposed "Integral } \\
\text { Planning Model" (IPM) }\end{array}$ \\
\hline
\end{tabular}

The proposed model, (mapping, abstracting, understanding and quantification), drew on statistics and mental mapping after abstracting information and drawing conclusions, (See Figure 2).

The value of the theory and model is realized, firstly by using mental mapping and secondly clarifying the issues to empower the imagination to understand problems facing the city. Finally, research and analysis explained the mental mapping, defining a priority of interventions, at metropolitan scale, thus providing a parametric matrix approach, that define in study tasks and analysis sections.

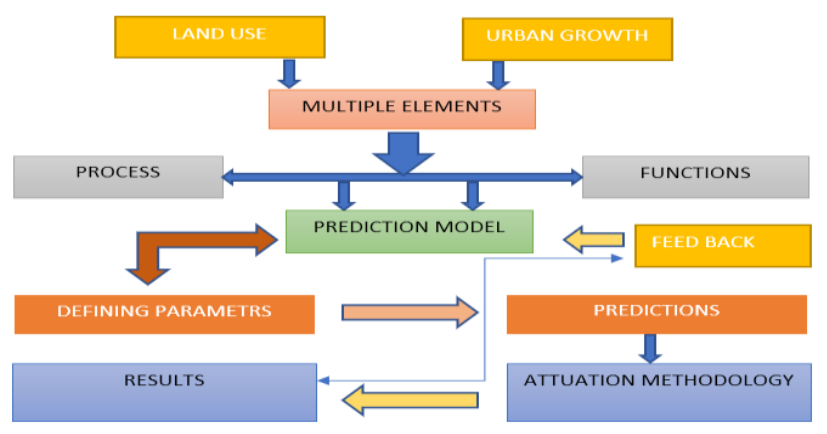

Figure 2. Integral model of planning (IPM), graphic framework illustration

This provided basic, but crucial information, which meant we could avoid the use of the spectrum models of planning employed by local planners. Such models are based on probable rather than empirical methodology. Cognitive analysis and evaluation allow to develop the design process and then get to verifiable proposals, and summarize the role of a theoretical model [19].

The proposed model of development and urban regeneration is based on scientific analysis, supported by critical investigation, (see attached 2,3, model matrix compilation). It includes a spatial analysis of various factors that influence land use to enhance understanding of the current state of urban evolution in Irbid. The "Integral Planning Model", (IPM), highlights:

- Factors and aspects of urban spatial changes being to be modelled.

- Which urban models used in the specific context.

- How to use data and software applying our model.

- Modelling methodology, the use of software and visualization tools might be appropriate for an urban changes modelling project, (the use of GIS principally in our case).

- Modelling benefits at medium and long-term planning.

\subsection{The proposed model's framework}

In this paper, the techniques used to build the proposed methodology is an integrated approach between the Traditional Spatial Modelling (TSM) and the Business Process Re-engineering (BPR), which will play a key role in the development process of AS-Is City (status of the city with its urban problems) into To-Be city (future planned status of the city based on sounded solution of the existing problems). Following will be a briefly introduction about BPR, TSM and Gravity model.

\subsubsection{Business process re-engineering (BPR)}

Business Process Re-engineering is a concept about improvement on a process. It is considered as a tool to change an organization process in order to achieve changes in critical aspects such as cost, quality of service, and speed [20]. The BPR framework is divided into 4 stages (See Table 5) which are:

- $\quad$ Stage 1: (To-Be) is the stage that focuses on defining organization's development goals.

- Stage 2: (As -Is) is the stage that is focuses on defining the existing business process.

- $\quad$ Stage 3: (The Plan stage) that is a planning process to realize As-Is stage into To Be stage.

- Stage 4: (The Crossing stage) that is an implementation planning process [21].

Table 5. Methodology used in developing matrix parameters

\begin{tabular}{ccc}
\hline Stage & Definition & Tools used \\
\hline (To-Be) & $\begin{array}{c}\text { Defining organization's } \\
\text { development goals. } \\
\text { Defining the existing business } \\
\text { process }\end{array}$ & $\begin{array}{c}\text { Meetings, interviews with users and } \\
\text { policy makers and academic figures }\end{array}$ \\
Planning process & $\begin{array}{c}\text { Planning process to realize As-Is } \\
\text { stage into To Be stage }\end{array}$ & $\begin{array}{c}\text { Comparing data; strengths and } \\
\text { weakness with other realities. }\end{array}$ \\
Crossing stage & Implementation planning process & $\begin{array}{c}\text { Highlighting parameters which } \\
\text { influence planning time realization }\end{array}$ \\
\hline
\end{tabular}




\subsubsection{Traditional spatial modelling}

A general class of models is called "spatial interaction" models, which says that the interaction between two places (cities, blocks, regions, etc.) is a function of the distance between these two places. Spatial interaction is the flow of goods, people, information, etc. between two places. Most generally, the interaction between two regions, in our case study the two regions the city before and after, (i) and (j) which are function of the properties of regions ( $i$ and $j$ ) and the "distance" between them. Relevant properties may include number of jobs, number of destinations, square feet of retail space, population, and income [22].

\subsubsection{Gravity model}

Based on Newtonian physics, Gravity models are the most known type of Spatial Interaction Model. The gravity model gives a new perspective to the investigation of spatial structure and makes easier the transport planning and land development modelling [23]. In fact, the potential models based on gravitational analogy are the most important groups of accessible models. The gravitational force exerted between any two point-like bodies is defined by; the product of their masses over the distance between them squared, times the universal gravitational constant $\mathrm{k}$ [24].

\subsection{The proposed "Integral Planning Model” (IPM)}

Based on Business Process Re-engineering and the Gravity model, which is the most known type of Spatial Interaction Model, the proposed technique which will be called a "Integral Planning Model" (IPM)) can be expressed as:

$$
T_{i, j}=k \frac{P_{i}^{\alpha} Q_{j}^{\beta}}{t_{i, j}^{\lambda}}
$$

where, $\mathrm{T}$ is the interaction between City status $\mathrm{i}$ (As-Is) and $\mathrm{j}$ (To-Be) as a function of a constant $\mathrm{k}$, and a measure of the "Problem" $(\mathrm{P})$ at city status $\mathrm{i}$ and the solution $(\mathrm{Q})$ at city status $\mathrm{j}$, over the time $(\mathrm{t})$ raised to some power lambda. Alpha and beta are parameters that can be estimated empirically using data on actual flows. In fact, in our case study $T$ represents the planning process to realize As-Is stage into To-Be stage.

Based on alternative time decay functions, and Newtonian physics, the proposed method can be simplified as in:

$$
T_{i, j}=k \frac{P_{i}^{\alpha} Q_{j}^{\beta}}{t_{i, j}^{\lambda}}
$$

To make the equation estimable, we take a logarithmic transformation:

$$
\ln T_{i, j}=\ln k+\ln P_{i}+\ln Q_{j}-2 \ln t_{i, j}
$$

The proposed technique would benefit the long-term planning by investigating the components and aspects of urban spatial change being to be modelled. In fact, it is expected to increase life quality and solve urban problems resolving past choices, characterized by irrational elements which fragment the impact factor of the solutions, (See Figure 3).

In Figure 4a, If the $\mathrm{X}$-axis represents (solution/problem) not connected to each other, and $\mathrm{Y}$-axis represents the impact factor of these solutions, then we have graphic, where elements of the Spectrum Model are represented as independent variables. The use of "Integral Planning Model" (IPM) in undeveloped city, as in our case, can be summarized as: if choices of solution adopted are part of a strategy, (part of a series or succession of phenomena, like Taylor series where the dependent variable can be represented as an infinite sum of terms that support each other in such a harmony environment), then the impact factor of these solutions will be amplified, as shown in the progression continuous graphic (Figure 4b), where elements of the Integral Model are represented not only as individual pieces, but also as actual parts of a series or succession interacting with each other. Note that in Figure 4a, the same theme of development is adopted, which can be mathematically modelled as an equation of the first rank $\mathrm{f}(\mathrm{x})=\mathrm{a}(\mathrm{x})$ for some (a) belongs to positive integers. On the contrary, in Figure $4 b$, there is a geometric progression, where successive terms are increasing with a constant ratio, which can mathematically be expressed as a geometric series. If the adequacy of each solution in both cases can be geometrically determined as the total area under the representative curve, then the total area is 2 in the first case, while it is 8 in the second case. There are several parameters to be concerned such as main problems of the city (traffic jams, etc.). After identifying problems of the As-is status of the city, then there will be a business process assessment about each problem.

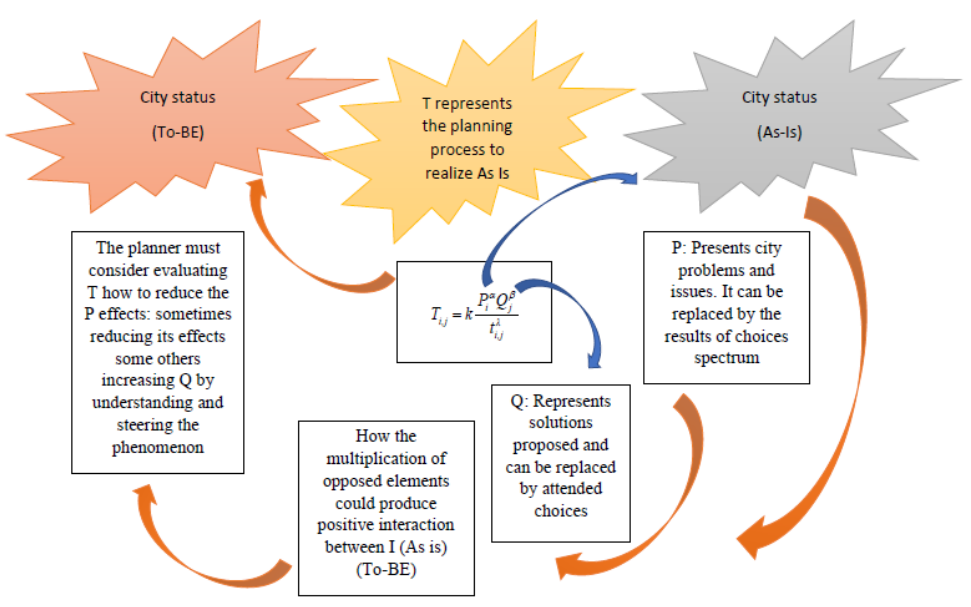

Figure 3. City status as-is and city to-be logarithm simplification 

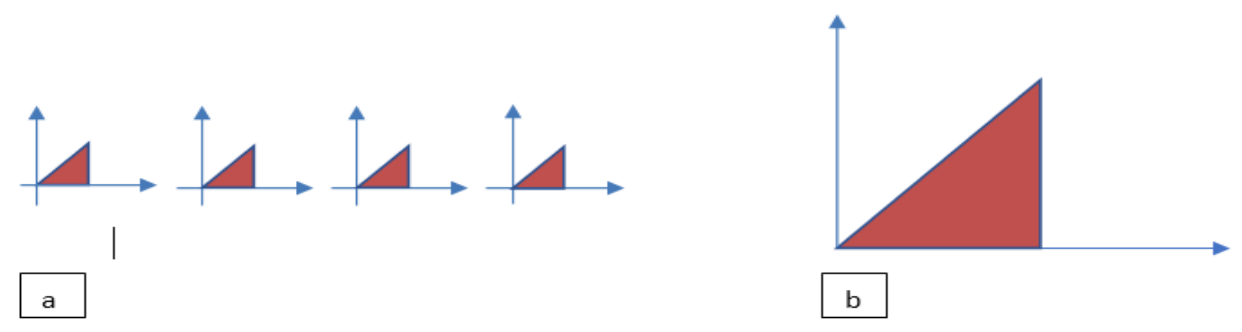

Figure 4. Shows (a) Conceptual discrete spectral model, (b) Progression continuous integral model

There are several parameters to be concerned such as main problems of the city (traffic jams, etc.). After identifying problems of the As-is status of the city, then there will be a business process assessment about each problem. The result from the business process assessment is required to be as detail as possible until its lowest level. This will enable the accuracy of solution that will be implemented. Then, reaching to a wellplanned solution that could be a system or an application to be implemented to form the "To-be" status of the city.

\section{RESULTS AND CONSIDERATIONS}

Drawing on the literature, we illustrate the importance of understanding the evolution of a city at various levels. A large view in different epochs and places, using different study cases should help to better formulate our hypothesis. It is not enough to simplify the demand innovate planning or keeping conservation approach [25].

An integral model of development based on the overall issue's comprehension is needed. Furthermore, models based on spectral analysis need to be abandoned in favor of integral models of development based on real analysis comprehension.

The interpretation model proposed study scenarios and analyses used in developed international and local cases individuating experiences that give a valid contribution and helps to develop future solutions to produce masterplans able to read problems related to our case study (Irbid) [26]. On the other hand, consider, firstly, the suggestions done by Lynch [27] on how space could be structured and represented using a shape and description of urbanization process. Secondly, consider suggestions done by Metropolitan Matrix Model. The proposed methodology develops a mental mapping of issues and difficulties that planners in Irbid may encounter. These issues cannot be solved by interventions targeting only physical issues. In addition, the use of theoretical interpretation models to understand the metropolitan qualitative shape definition and metropolitan architecture identity was discussed according to three urban metabolism paradigms: maintain and conserve, substitute and develop, and transform and grow.

\subsection{Proposed "Integral Planning Model" (IPM) application in the case study}

From the analysis, it can say that many planning problems in Irbid city can be attributed to the inability of the policymakers to actuate decisions in the different sectors. However, this does not mean that there is an absence of qualified professional bodies or a lack on the advanced resources rather than the fragmented adopted methodologies to deal with the rapid and informal urbanization. The decisions of the local administration during the rehabilitation process in the last years are characterized by the impossibility of execution and they do not present a plan that covers the overall problem. The proposed model aims to assist the policymakers to have the right strategy to deal with these complicated issues. The first application of this model was to divide interventions into strategies abandoning the fragmented method, as shown in Figure 3a, 3b the efficiency of the strategy that collect different factors is better than the one which affronts problem in a singular mode within organizing and simplifying processes. The second application of the proposed model consists of simplifying the consultation process where many decisions are taken according to the different social, political and economic aspects and the use of the priority matrix to be compiled by the different advisers to highlight the most important interventions. Such the proposed model contributes to reducing decision fragmentation (See Figure 4). This method validates strategies that take into consideration real problems abandoning the spectral method of planning used in Irbid city during the last years as described below (paragraph 4.1).

The proposed "Integral Planning Model" (IPM) with the use of the matrix divide issues in parameters, thus, multiple advisers or specialists should be able to analyze different issues with relative mind set (without being influenced by the fragmentation which characterizes the current method of planning where it is difficult to have a decision that is acceptable by the community). The proposed "Integral Planning Model" (IPM) introduces a priority logarithm and mathematical vision address that set strategies to select interventions with major impact on the future of the city reducing fragmentations in the social, technical, and academic debate. The proposed "Integral Planning Model" (IPM) improves the general debate on the future of the city giving all parts the possibility to express needs and visions but at the same time address them to select the most shared positions, in this way, time and resources are managed better. The proposed "Integral Planning Model" (IPM) is a theoretical instrument, which deals with parameters that play a crucial role with the finality to simplify the policymaker decision offering a prediction methodology. The policymaker can adopt the cited model to investigate and to simulate impacts of some choices on territory and on decision partners as community representatives, academicians and different planning authorities compiling the matrix independently. The sum of results represents the level of sharing issues-solutions, the future strategy of selecting the highly shared strategies.

\subsection{How the proposed methodology is implemented in the case study}

The planning difficulties in Irbid city as discussed in this paper are referred to as the inability of competent parts to start execution of the different master plans for the city due to the 
fragmented political, social and academic debate on the future of the city. Contrapositions within this debate impede the possibility to have shared positions, thus plans for developing the city do not express the real needs with dramatic results, as discussed in this paper. The proposed "Integral planning Model" (IPM) is based on the use of parametric development of issues and feedback of parts playing role in the planning process called model matrix (see Table 6), which represent a different approaches by giving different weights to the factors that positively or negatively increase the development of the city. Firstly, within different parts playing a role in the planning process are called to respond separately. This method helps to have a parametric decision abandoning one based on personal interests, different philosophical positions of different planning institutions. The compilation of the cited matrix (which is basically is the background of our prediction model "Integral planning Model" (IPM)) gives mathematical and statistical information easily interpretable by all the below cited parts. The first important result that policymakers are assisted empirically is that the decisions based on spectral positions should be gradually abandoned. The second result implies that all the interested parts in the planning process will consider decisions obtained in this way suitable for increasing the level of shared values. Table 6 summarizes the proposed methodology, among specialists' interviews, we collect the weight of elements that accelerate or relay the sustainable development in our specific case with finality to produce real proposals draft. The potentiality of the method is the exclusion or inclusion of interventions in a strategy automatically. Thus, we obtain rational debates on what to do, working on homogeneous decision layers.

Table 6. Integral Planning Model (IPM) matrix compilation model

(Model matrix: Analysis of interviews) T, Interaction City status i (As-Is) and j (To-Be) decay time based on analyses of big data, academic and policymakers', users' interviews.

\begin{tabular}{|c|c|c|c|c|c|c|c|c|c|c|c|c|c|c|c|c|c|c|c|c|c|c|c|c|}
\hline \multirow{2}{*}{\multicolumn{2}{|c|}{ Parametric crossing coverage }} & \multicolumn{23}{|c|}{ Planning process As-Is (issues that increase (beta coefficient of relay of development) } \\
\hline & & \multicolumn{4}{|c|}{ Traffic issues } & \multicolumn{5}{|c|}{ Territory policies } & \multicolumn{6}{|c|}{ Social, economic policies } & \multicolumn{7}{|c|}{ Design elements } & \multirow[b]{2}{*}{ 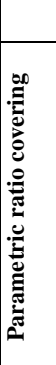 } \\
\hline \multicolumn{2}{|c|}{$\begin{array}{l}\text { Planning process to realize } \\
\text { To-Be stage. (issues that } \\
\text { increase (alpha coefficient of } \\
\text { acceleration of development)) }\end{array}$} & 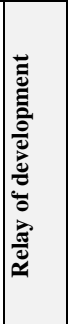 & 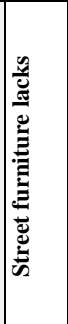 & 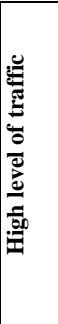 & 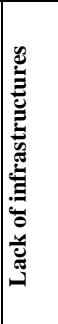 & 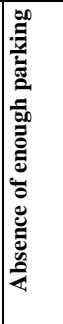 & 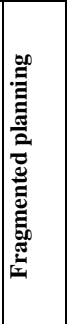 & 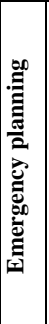 & 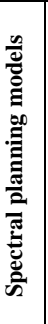 & 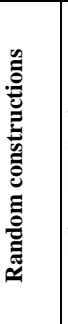 & 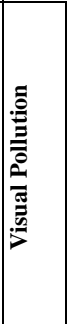 & 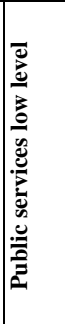 & 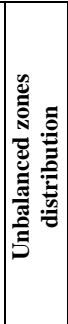 & 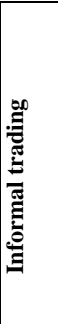 & 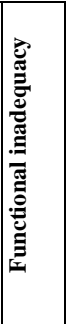 & 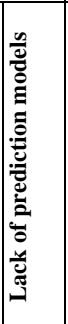 & 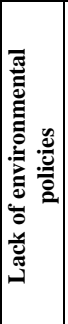 & 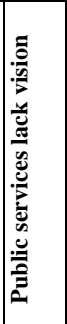 & 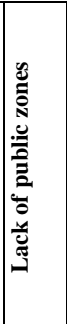 & 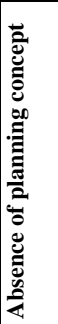 & 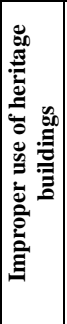 & 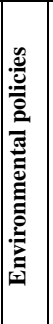 & 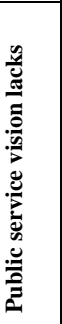 & \\
\hline \multicolumn{2}{|r|}{ Acceleration development } & & 61 & 77 & 82 & 72 & 72 & 75 & 57 & 62 & 61 & 73 & 71 & 69 & 66 & 67 & 70 & 78 & 63 & 60 & 71 & 70 & 68 & \\
\hline \multirow{6}{*}{ 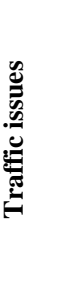 } & Infrastr. modernization & 72 & 11 & -5 & -10 & $\mathbf{0}$ & $\mathbf{0}$ & -3 & 15 & 10 & 11 & -1 & 1 & 3 & 6 & 5 & 2 & -6 & 9 & 12 & 1 & 2 & 4 & 67 \\
\hline & Traffic solution & 86 & 25 & 9 & 4 & 14 & 14 & 11 & 29 & 24 & 25 & 13 & 15 & 17 & 20 & 19 & 16 & 8 & 23 & 26 & 15 & 16 & 18 & 361 \\
\hline & Public transportations. & 92 & 31 & 15 & 10 & 20 & 20 & 17 & 35 & 30 & 31 & 19 & 21 & 23 & 26 & 25 & 22 & 14 & 29 & 32 & 21 & 22 & 24 & 487 \\
\hline & Parking areas. & 87 & 26 & 10 & 5 & 15 & 15 & 12 & 30 & 25 & 26 & 14 & 16 & 18 & 21 & 20 & 17 & 9 & 24 & 27 & 16 & 17 & 19 & 382 \\
\hline & land consump. reduction & 71 & 10 & -6 & -11 & -1 & -1 & -4 & 14 & 9 & 10 & -2 & $\mathbf{0}$ & 2 & 5 & 4 & 1 & -7 & 8 & 11 & $\mathbf{0}$ & 1 & 3 & 46 \\
\hline & Pedestrian zones and paths & 90 & 29 & 13 & 8 & 18 & 18 & 15 & 33 & 28 & 29 & 17 & 19 & 21 & 24 & 23 & 20 & 12 & 27 & 30 & 19 & 20 & 22 & 436 \\
\hline \multirow{6}{*}{ 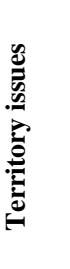 } & Creating green spaces. & 87 & 26 & 10 & 5 & 15 & 15 & 12 & 30 & 25 & 26 & 14 & 16 & 18 & 21 & 20 & 17 & 9 & 24 & 27 & 16 & 17 & 19 & 382 \\
\hline & Land metabolism. & 71 & 10 & -6 & -11 & -1 & -1 & -4 & 14 & 9 & 10 & -2 & $\mathbf{0}$ & 2 & 5 & 4 & 1 & -7 & 8 & 11 & $\mathbf{0}$ & 1 & 3 & 46 \\
\hline & Recover historical areas & 74 & 13 & -3 & -8 & 2 & 2 & -1 & 17 & 12 & 13 & 1 & 3 & 5 & 8 & 7 & 4 & -4 & 11 & 14 & 3 & 4 & 6 & 109 \\
\hline & Smart models for city & 83 & 22 & 6 & 1 & 11 & 11 & 8 & 26 & 21 & 22 & 10 & 12 & 14 & 17 & 16 & 13 & 5 & 20 & 23 & 12 & 13 & 15 & 298 \\
\hline & Buildings density & 72 & 11 & -5 & -10 & $\mathbf{0}$ & $\mathbf{0}$ & -3 & 15 & 10 & 11 & -1 & 1 & 3 & 6 & 5 & 2 & -6 & 9 & 12 & 1 & 2 & 4 & 67 \\
\hline & vertical horizontal ratio & 69 & 8 & -8 & -13 & -3 & -3 & -6 & 12 & 7 & 8 & -4 & -2 & $\mathbf{0}$ & 3 & 2 & -1 & -9 & 6 & 9 & -2 & -1 & 1 & 4 \\
\hline \multirow{6}{*}{ 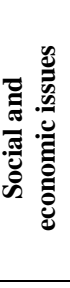 } & Distribution interventions & 70 & 9 & -7 & -12 & -2 & -2 & -5 & 13 & 8 & 9 & -3 & -1 & 1 & 4 & 3 & $\mathbf{0}$ & -8 & 7 & 10 & -1 & $\mathbf{0}$ & 2 & 25 \\
\hline & City functional diversity & 69 & 8 & -8 & -13 & -3 & -3 & -6 & 12 & 7 & 8 & -4 & -2 & $\mathbf{0}$ & 3 & 2 & -1 & -9 & 6 & 9 & -2 & -1 & 1 & 4 \\
\hline & Reviewing zoning. & 71 & 10 & -6 & -11 & -1 & -1 & -4 & 14 & 9 & 10 & -2 & $\mathbf{0}$ & 2 & 5 & 4 & 1 & -7 & 8 & 11 & $\mathbf{0}$ & 1 & 3 & 46 \\
\hline & Residential-economic ratio & 73 & 12 & -4 & -9 & 1 & 1 & -2 & 16 & 11 & 12 & $\mathbf{0}$ & 2 & 4 & 7 & 6 & 3 & -5 & 10 & 13 & 2 & 3 & 5 & 88 \\
\hline & quality of cultural spaces. & 76 & 15 & -1 & -6 & 4 & 4 & 1 & 19 & 14 & 15 & 3 & 5 & 7 & 10 & 9 & 6 & -2 & 13 & 16 & 5 & 6 & 8 & 151 \\
\hline & Decentralization & 76 & 15 & -1 & -6 & 4 & 4 & 1 & 19 & 14 & 15 & 3 & 5 & 7 & 10 & 9 & 6 & -2 & 13 & 16 & 5 & 6 & 8 & 151 \\
\hline \multirow{4}{*}{ 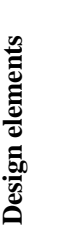 } & Innovative design & 73 & 12 & -4 & -9 & 1 & 1 & -2 & 16 & 11 & 12 & $\mathbf{0}$ & 2 & 4 & 7 & 6 & 3 & -5 & 10 & 13 & 2 & 3 & 5 & 88 \\
\hline & Open space activities & 74 & 13 & -3 & -8 & 2 & 2 & -1 & 17 & 12 & 13 & 1 & 3 & 5 & 8 & 7 & 4 & -4 & 11 & 14 & 3 & 4 & 6 & 109 \\
\hline & $\begin{array}{l}\text { Verticality to incentivize } \\
\text { public spaces, }\end{array}$ & 73 & 12 & -4 & -9 & 1 & 1 & -2 & 16 & 11 & 12 & $\mathbf{0}$ & 2 & 4 & 7 & 6 & 3 & -5 & 10 & 13 & 2 & 3 & 5 & 88 \\
\hline & $\begin{array}{l}\text { Innovative urban - } \\
\text { architectural concepts }\end{array}$ & 82 & 21 & 5 & $\mathbf{0}$ & 10 & 10 & 7 & 25 & 20 & 21 & 9 & 11 & 13 & 16 & 15 & 12 & 4 & 19 & 22 & 11 & 12 & 14 & 277 \\
\hline \multicolumn{25}{|c|}{ Parameters ratio covering } \\
\hline
\end{tabular}




\subsection{Proposals based on the Integral Planning Model (IPM)}

This paper highlighted and evidenced the necessity to introduce new technological methods and new logarithms of thinking to address the dramatic reality of the city. Pure acting with traditional methods in analysis regarding the development process in Irbid we individuate some proposals:

(1) The use of analytical methods of data collection necessary to develop a decision. The use of the proposed matrix in our model permits to have a description of the reality without being influenced by any ideology or residual thinking, witnessed the multiple element that pollute a planning process.

(2) The use of "smart collective decisions" based on the use of Integral Planning Model (IPM). As evidenced in this paper one of major problems that policy makers affront is how to have suitable and shared decision. The proposed method limits discussion by the individuation of highest impact elements. Thus, it is possible to reduce time decision.

(3) Opening the planning process to major number of advisers with different formation backgrounds. The matrix method can individuate the most important needs and priorities.

(4) The use of different layers produced by the analytical methods to produce the necessary overlapping of issues in a strategy and at the same time the possibility to act on separate layers.

(5) As proposal and result, breaking the monopoly of the planning process of Irbid. Thus, the future of the city is not controlled by a reduced number of persons minimizing their error possibilities.

(6) Introduction of simulations in the planning process based on the use of prediction models, as the proposed Integral Planning Model (IPM) opening a valid debate on the future modelling and shaping the city.

(7) The proposals will make it possible to formulate guidelines on how best to regenerate the city and put forward proposals and solutions to current problems in the city. In long-term plan for Irbid.

This long-term vision introduces the possibility of Irbid as a smart model city, which may seem paradoxical, given the status of the city. However, we think that this vision provides the possibility of connecting various interventions and predicting the future of the city.

\section{CONCLUSIONS}

This study focused on complex elements that are impeding the development of Irbid. Rather than identifying physical interventions, to create sustainable planning model of interpretation and prediction the conditions responsible for underdevelopment and potential conditions that can aid development need to be understood.

This model contrasts the spectrum vision diffused by local planners and present among users. The present study highlighted how this vision influenced, negatively, on the overall process of urbanization in Irbid. The proposed integral model proposed is based on a "mathematical concept" that focus on organizing the process correcting the strategies to be adopted. In this paper, we identified the matrix of elements that do not permit sustainable evolution and the weight of each elements that plays crucial roles in the city's evolution. The results highlighted the impossibility of progressing using fragmented interventions and the necessity to give a parametric vision of issues and strategies.

To encourage urban sustainable design, a new strategy is needed, in which Irbid's center is integrated with the rest of the city. Focusing on this mode of evolution and developing functional connections between its parts can lead to new approaches, as well as ways of thinking about architectural and urban regeneration and design. Reduced consumption (in the present case: land and space) is one of the principal elements of a sustainable culture. Urban regeneration Irbid requires a drastic reduction of land metabolism with policies that favor vertical growth and limit growing in agricultural areas around the city and sustainable vision for urban interventions strategies. The term "sustainable," as employed today, depends on a clear understanding of the impacts of design parametric and approaches.

We conclude that the Integral Model of Planning (IPM), which is based on a "mathematical vision" that allows for partial actions in an approach within different realities is part of a unique mosaic and combines preservation and innovation, as well as intelligent ideas, such as smart cities concepts, sustainable and green solution that can be used to enhance the quality of life in Irbid city.

For future research we will define the development of the cited model by the definition of parameters and variables that could define issues among informatics with feedback systems that allow getting similar results from different and heterogeneous factors. Also, processes stages will be accurately identified as well as applying the proposed model empirically using real data to estimate the parameters of the proposed model.

\section{REFERENCES}

[1] Al Suery Muhamed. (2006). Irbid; History, Civility and Ruins, (in Arabic). First edition by Greeter Amman Municipality, Amman, Jordan, 248-251.

[2] Salibi K.S. (1998). The Modern History of Jordan. I.B. Tauris; Revised ed.

[3] Al-kheder, S., Haddad, N., Fakhoury, L., Baqaen, S. (2009). A GIS analysis of the impact of modern practices and policies on the urban heritage of Irbid, Jordan. Cities, 26(2): 81-92. https://doi.org/10.1016/j.cities.2008.12.003

[4] Aldeek, Z.A.O. (2017). The evolution of the city of Irbid from a small centre into a metropolis. Digital Library. https://doi.org/10.5176/2301-394X_ACE17.79

[5] Tarrad, M. (2014). Urban planning response to population growth in Jordanian cities (Irbid city as case study). Research Journal of Applied Sciences, Engineering and Technology, 20: 4275-4280. https://doi.org/10.19026/rjaset.7.799

[6] Local Economic Development Strategy for Irbid Governorate 2016-2018. International Labour Organization - Beirut: ILO, 2016. https://www.ilo.org/wcmsp5/groups/public/--arabstates/---robeirut/documents/publication/wcms_456503.pdf

[7] Al Sayyed, W. (2011). Tradition versus modernity from cultural discourse to architectural Crisi. Lonaard Magazine is a peer-reviewed periodical, publication of Lonaard Group in London, 6(1): 72-91.

[8] Fathy, H. (1973). Architecture for the Poor: An 
Experiment in Rural Egypt. Chicago \& USA: The University of Chicago Press.

[9] Rossi, A., Eisenman, P. (1982). The Architecture of the City. MIT Press, Cambridge, MA.

[10] Al-Omari. B.H., Obaidat E.S. (2013). Analysis of pedestrian accidents in Irbid City, Jordan. The Open Transplantation Journal, 7(1): 1-6.

[11] Forlani, M.C. (2015). Local development/sustainable development. New integrations between «city and countryside». TECHNE - Journal of Technology for Architecture and Environment, (10), 85-92. https://doi.org/10.13128/Techne-17504

[12] Beauregard, R., Marpillero-Colomina, A. (2010). More than a master plan: Amman 2025. Cities, 28(1): 62-69. https://doi.org/10.1016/j.cities.2010.09.002

[13] Alloni, M., Botta, M. (2012) Mario Botta-Vivere L'architecture (In Italian). Casagrande Editor, Casagrande, 232 pages.

[14] Ali, H.H., Al-Betawi, Y.N., Al-Qudah, H.S. (2019). Effects of urban form on social sustainability - A case study of Irbid, Jordan. International Journal of Urban Sustainable Development. 11(2): 203-222. https://doi.org/10.1080/19463138.2019.1590367

[15] Marc Aurel Schnabel (2008). Parametric Design in Urban Design. ICCCBE-XII \& INCITE October 16-18, 2008, Beijing, China. (C2008 Tsinghua University Press \& Springer.

[16] Ai-Kofahi, S.D., Hammouri, N., Sawalhah, M.N., AlHammouri, A.A., Aukour, F.J. (2018). Assessment of the urban sprawl on agriculture lands of two major municipalities in Jordan using supervised classification techniques. Arabian Journal of Geosciences, 11: 45. https://doi.org/10.1007/s12517-018-3398-5

[17] Contin, A., Ortiz, P.B., Zammataro, A. (2014). Metro matrix model for a non-fragmented city: the new metropolitan morph-type, such as a grey and green geographical skin of the infrastructure. Eurau 2014, Composite Cities, Istanbul-Turkey, 1-12.
[18] Mihail, S., Nimit, C., Namchul, S. (2003). An investigation of the methodologies of business process reengineering. Proc ISECON 2003, v20 (San Diego): $\$ 2123$.

[19] Cheng, J., Masser, I. (2004). Understanding spatial and temporal processes of urban growth: Cellular automata modelling. Environment and Planning B: Planning and Design, 31(2): 167-194. https://doi.org/10.1068/b2975

[20] Akhavan, P., Jafari, M., Ali-Ahmadi, A.R. (2006). Exploring the interdependency between reengineering and information technology by developing a conceptual model. Business Process Management Journal, 12(4): 517-534. https://doi.org/10.1108/14637150610678104

[21] Stewart, J.Q. (1948). Demographic gravitation: Evidence and applications. Sociometry, 11(1-2): 31-58. https://doi.org/10.2307/2785468

[22] Budó, Á. (2004). Experimental Physics I. National Textbook Press, Budapest.

[23] Anas, A. (1983). Discrete choice theory, information theory and the multinomial logit and gravity models. Transportation Research Part B: Methodological, 17(1): 13-23. https://doi.org/10.1016/0191-2615(83)90023-1

[24] Fan, Y., Zhang, S., He, Z.Y., He, B., Yu, H.C., Ye, X.X., Yang, H., Zhang, X.M., Chi, Z.F. (2018). Spatial pattern and evolution of urban system based on gravity model and whole network analysis in the Huaihe River Basin of China. Discrete Dynamics in Nature and Society, 2018: 3698071, 11

pages. https://doi.org/10.1155/2018/3698071

[25] Batty, M. (2008) The size, scale, and shape of cities. Science, $319(5864)$ : 769-771. https://doi.org/10.1126/science.1151419

[26] Abu-Hamdi, E. (2017). Neoliberalism as a site-specific process: The aesthetics and politics of architecture in Amman, Jordan. Cities, 60(Part A): 102-112. https://doi.org/10.1016/j.cities.2016.08.001

[27] Lynch, K. (1976). Managing the Sense of a Region. MIT Press: Cambridge, Massachusetts, USA. 